\title{
The Effect of Gestational Age on the Effective Elastance of the Respiratory System in Neonates
}

\author{
RODNEY B. BOYCHUK, MARY M. K. SESHIA, AND HENRIQUE RIGATTO'15! \\ Department of Pacdiatrics, University of Manitoba, Winnipeg, Manitoba, Canada
}

\begin{abstract}
Summary
We measured the effective elastance of the respiratory system $\left(\mathrm{E}^{\prime}{ }_{\mathrm{RS}}\right)$ in 38 "healthy" neonates, gestational ages ranging from 28-42 weeks. $E^{\prime}{ }_{n S}$ was calculated by dividing the inspiratory pressure generated after nasal occlusion by the tidal volume of the breath preceding occlusion $\left(\mathbf{E}_{\mathrm{RS}}^{\prime}=\mathbf{P} / \mathbf{V}_{\mathrm{T}}\right)$. $\mathbf{E}_{\mathrm{HS}}^{\prime}$ decreased from $790 \pm 0.070 \mathrm{~cm} \mathrm{H}_{2} \mathrm{O} /$ liter at $30.4 \pm 0.4$ weeks of gestation to $520 \pm 0.030$ at $34.5 \pm 0.3$ weeks $(P<0.01)$; then to $340 \pm$ 0.020 at $40 \pm 0.2$ weeks $(P<0.01)$. $E^{\prime}{ }_{k s}$ corrected for lung volume ("specific" $E^{\prime}{ }_{R S}$ ) were $32 \pm 2,32 \pm 4$, and $28 \pm 2 \mathrm{~cm}$ $\mathrm{H}_{2} \mathrm{O}$ at the above gestational ages, respectively $(P>0.05)$. We suggest: (I) the increased $\mathrm{E}^{\prime}{ }_{\mathrm{nS}}$ observed in preterm infants is lung volume dependent. Changes in lung volume may alter the geometry of the thorax, and therefore, the force/length characteristics of the respiratory muscles; (2) this increased $E^{\prime}{ }_{k s}$ is not of much benefit to preterm infants who have little respiratory stability when $E^{\prime}{ }_{R S}$ is maximum; and (3) if $E^{\prime}{ }_{R S}$ is an index of mechanical stability, apnea in preterm infants is independent of the mechanical properties of the respiratory system.
\end{abstract}

\section{Speculation}

The price of increased $E_{R S}^{\prime}$ in premature infants is greater work of breathing, and the reward is increased stability of ventilation. It may be that the reward is not worth the price. The increased $\mathrm{E}_{\mathrm{HS}}^{\prime}$, by excessive work demand, may actually predispose these infants to respiratory instability.

The effective elastance of the respiratory system has been accepted traditionally as an index of ventilatory stability (4-6). The greater the $E^{\prime}{ }_{n s}$, the more stable the respiratory system would be. We wanted to know whether changes in such an index parallel the changes in respiratory stability as assessed clinically, i.e., whether $\mathrm{E}^{\prime}{ }_{\mathrm{ns}}$ is low when periodic breathing and apnea are common. Secondly, we wanted to discover whether the eventual changes in $E_{k s}^{\prime}$ could be attributed to changes in lung volume. Previous observations suggested that $E^{\prime}{ }_{k s}$ was greatest when the incidence of apnea is usually highest, i.e., when the infant is very premature $(1,2,8)$. In one of these studies $(8)$ differences in I: ${ }_{\text {His }}$ remained after corrections were made for lung volume, but in another (1) they were almost abolished, except in infants between 29-32 weeks of gestation, whose elastances remained higher than that of infants born at term. In the present study we reassessed the changes in $E_{\text {Hs }}^{\prime}$ with increasing gestational age and the volume dependency of these changes.

\section{SUBJECTS AND METHODS}

\section{SUBJECTS}

Thirty-eight "healthy" newborn infants were studied on 1 or 2 occasions each during the first 3 days of life. They were divided into three groups according to gestational age. Mean gestational ages and birth weights $( \pm$ SE) were $30.4 \pm 0.4$ weeks, $1,392 \pm$
$60 \mathrm{~g}$ (group $l ; n=15) ; 34.5 \pm 0.3$ weeks, $1,967 \pm 103 \mathrm{~g}$ (group) $I I ; n=13)$; and $40.0 \pm 0.2$ weeks, $3,282 \pm 86 \mathrm{~g}$ (group lll;; $n=$ 10), respectively.

\section{METHODS}

The methods have been described in detail previously (10). Briefly, we modified our nosepiece by adapting a plunger (9) to allow for complete nasal occlusion (Fig. 1). We used a constant background flow (preterm 2.7 liters/min; term 3.7 liters/min) to eliminate valves and reduce dead space. This flow was electrically balanced to an artificial zero. The baby breathed through the nostril adaptors and added to or subtracted from this background flow. The electrical signal was integrated to give volume. We sampled inspired and expired gases using a fine catheter (PE 20) attached to one nostril adaptor. Nasal pressure was measured using a similar catheter attached to the other nostril adaptor and connected to a pressure transducer (Statham PM 5()). All recordings were made on a Brush polygraph (model 480$)$ ).

\section{PROCEDURE}

The study was explained to the mother and her consent obtained. All babies were studied on the Ohio Neonatal Intensive Care Unit shortly after a feed (mean abdominal skin temperature was $36.5 \pm 0.0\left(04^{\circ}\right)$. Xylocaine ointment was applied lightly to the baby's nostrils and around the nostril adaptors in order to anesthetize the skin and provide an airtight seal around the adaptors. The baby's mouth was gently held closed during the study.

The infants breathed $21 \% \mathrm{O}_{2}, 21 \% \mathrm{O}_{2}$ plus $2 \% \mathrm{CO}_{2}$, then $21 \% \mathrm{O}_{2}$ plus $4 \% \mathrm{CO}_{2}$ for 5 min each. Nasal occlusions, using the plunger, were carried out at endexpiration after the infant attained a steady state with each inspired gas mixture. Each occlusion was maintained for at least one complete breath. The infants tolerated the procedure well and generally slept quietly throughout the study, although they tended to be more restless with $4 \% \mathrm{CO}_{22}$. A representative tracing is shown in Figure 2.

\section{ANALYSIS}

Occlusions were done at regular intervals while the infant was breathing the various gas mixtures. We chose two to four occlusions from each gas concentration. The choice was based on technical excellency of occlusion, i.e., occlusion made exactly at end-expiration while the infant was quietly asleep.

We divided the inspiratory pressure generated after occlusion by the tidal volume $\left(\mathrm{V}_{\mathrm{T}}\right)$ of the breath preceding occlusion (control breath) to calculate effective elastance $\left(E^{\prime}{ }_{k s}=P / V_{p}\right)$ (4). E'rs did not change with the various studies $(4,6)$. "Specific" $E_{\text {RS }}^{\prime}$ was calculated using functional residual capacities (FRC) derived from previous data for similar weights and postnatal ages (4-8).

We compared E' ${ }_{\text {ns }}$ and "specific" E' ${ }_{\text {rs }}$ of the three groups of infants using the unpaired $t$-test. 


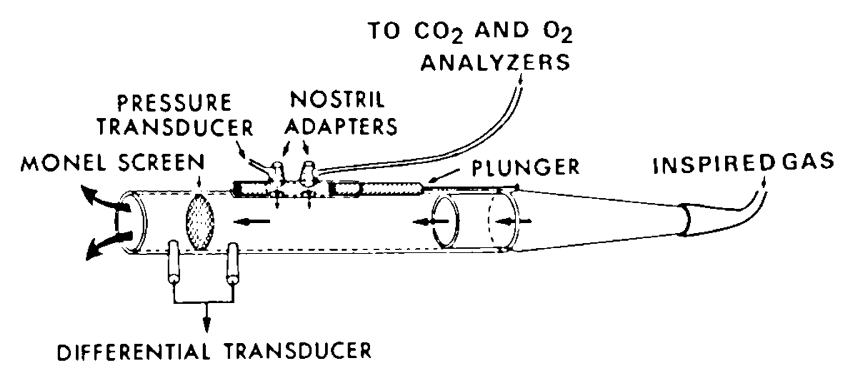

Fig. 1. Modified nosepiece with a plunger to occlude the nostrils at end-expiration.

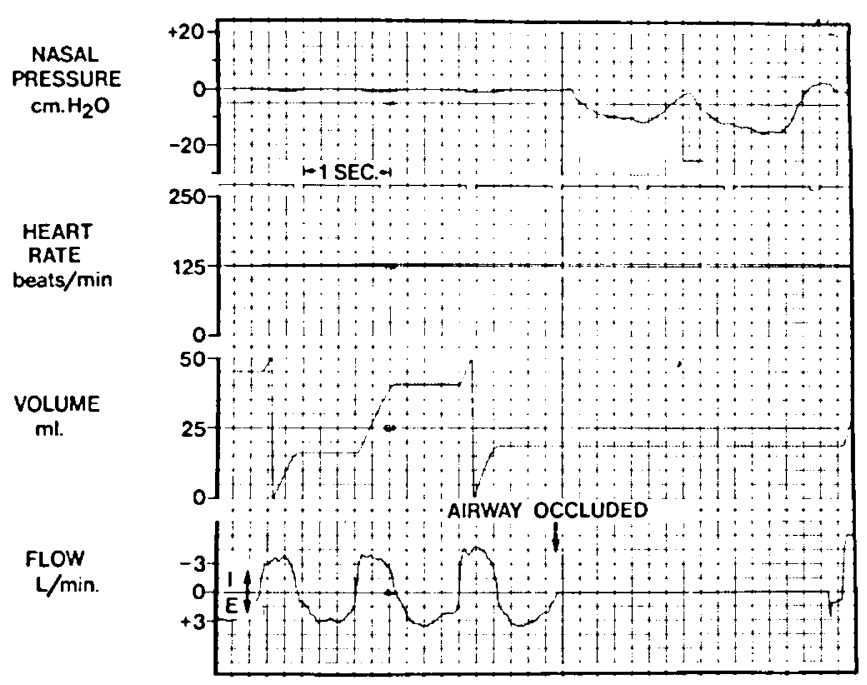

Fig. 2. Representative tracing in infant Be (2 days). Nasal occlusion was performed at end-expiration. To calculate $E_{\text {ns }}^{\prime}$, negative pressure generated after ocelusion is divided by the tidal volume of the preceding breath.

\section{LIMITATION OF METIIODS}

Assuming FRC from other data may introduce errors in the calculation of "specific" elastance. However, measurements of FRC using different methods have produced essentially the same values per unit of body weight or length $(3,7)$. We believe. therefore, the error to be small and likely to be on the absolute value of "specific" $E^{\prime}{ }_{n s}$ rather than on the relative changes with progressive ages.

In addition, inspiratory time $\left(\mathrm{T}_{1}\right)$ varies and peak nasal pressure is more difficult to measure with active but not with quiet sleep (2). We have not monitored sleep state and this might have affected our results. I owever, respiration was essentially regular preceding occlusion, as it usually is during the first 3 day's of life. Furthermore, $T_{1}$ was remarkably constant during the period preceding occlusion. We believe, therefore, that the respiratory pattern preceding occlusion was more consistent with quict sleep and errors due to sleep state are unlikely to have altered our results.

\section{RESULTS}

The E' ${ }_{R . S}$ decreased from $790 \pm 0.070 \mathrm{~cm} \mathrm{H.2}$ /liter at $30.4 \pm$ 0.4 weeks of gestation (group $l ; n=15)$ to $520 \pm 0.030$ at 34.5 \pm 0.3 weeks (group $I I ; n=13(P<0.01)$, and then to $340 \pm$ 0.020 at $40 \pm 0.2$ weeks (group $I I I ; n=10)(P<0.01)$. Specific $E^{\prime}{ }_{\text {Rs }}$ values were $32 \pm 2,32 \pm 4$ and $28 \pm 2 \mathrm{~cm} \mathrm{H} \mathrm{H}_{2} \mathrm{O}$ at the above gestational ages, respectively $(P>0.05)$ (Table 1 , Fig. 3).

\section{DISCUSSION}

We found that $E^{\prime}{ }_{\text {ns }}$ decreased with increasing gestational age, but "specific" $E^{\prime}{ }_{k s}$ did not. These findings suggest that differ- ences in $E^{\prime}{ }_{R s}$ at varying gestational ages are lung volume dependent. Once corrections are made for changing volumes. $E_{\text {n. }}$ remains the same from as early as $28-42$ weeks of gestation. How lung volume accounts for the changes in $E^{\prime}$ is is not clear, but it may modify the geometry of the thorax, and therefore, change the intrinsic properties of the respiratory muscles.

The difference between our findings and those of Olinsky et al. (9) resides on the magnitude of the calculated $E^{\prime}$ us and not on the estimated FRC (8). Our groups $I I$ and $I I I$ are comparable, in terms of body length or weight, to their groups of preterm and term infants, respectively. FRC of their infants, estimated on the basis of body weight, would have been 0.057 and 0.092 liters instead of 0.047 and 0.088 liters as calculated per body length, and therefore, "specific" $\mathrm{E}_{\mathrm{RS}}$ would have remained essentially' unchanged. However, the $E_{\text {ns }}^{\prime}$ ratio of their group of preterm/ term infants was 2.5 and that of our gromps $I I / I I I$ was only 1.5 . The reason for this discrepancy is not clear, but we wonder whether differences in postnatal age of their population might have affected the measured $E^{\prime}{ }_{k s}$.

Our findings are more in agreement with those of Adler $e^{\prime}$ al. (1). Indeed, at corresponding gestational ages, our values for $E^{\prime}{ }_{\text {ns }}$ are very similar to theirs. However, these investigators found a slightly increased "specific" $E^{\prime}$ 's at 29-32 weeks in relation to 33-36 or 39-41 weeks of gestation. Unfortunately. their group at 29-32 weeks is rather small $(n=5)$ and they do not mention how they estimated lung volume.

The $E^{\prime}{ }_{\text {rs }}$ depends on: (1) passive elastance of the lungs and chest wall; (2) the intrinsic properties of the respiratory muscles; and (3) neural recruitment of the intercostal muscles (4-6). The passive elastance, corrected for lung volume ("specific" passive clastance), appears to be similar in preterm and term infants (9). The intrinsic properties of the respiratory muscles may be altered by lung volume. The fact that correction of $E^{\prime}$ es for lung volume ("specific" $E^{\prime}{ }_{n s}$ ) eliminates the differences in $E^{\prime}$ ks sug-

Table 1. Effective and "specific" effective elastances of respiratory system $\left(E^{\prime}{ }_{R S}\right)$ at various gestational ages

\begin{tabular}{|c|c|c|c|c|c|c|}
\hline Groups & $\begin{array}{l}\text { Gesta- } \\
\text { tional } \\
\text { age, } \\
\text { weeks }\end{array}$ & $\begin{array}{l}\text { Birth } \\
\text { wt, g }\end{array}$ & $\begin{array}{c}\text { Age, } \\
\text { hr }\end{array}$ & $\begin{array}{c}\mathrm{E}_{\mathrm{Hs}}^{\prime} \\
\mathrm{cm} \\
\mathrm{H}_{2}, \mathrm{O} / \mathrm{li}- \\
\mathrm{ter}\end{array}$ & $\begin{array}{c}\text { FRC.' li- } \\
\text { ters }\end{array}$ & $\begin{array}{l}\text { "Spe- } \\
\text { cific" } \\
\mathrm{E}^{\prime} \mathrm{ks} \\
\text { cm } \mathrm{H}_{2} \mathrm{O}\end{array}$ \\
\hline$I$ & 30.4 & 1.392 & 35 & 790 & 0.0 .42 & 32 \\
\hline$(n=15)$ & \pm 0.4 & \pm 60 & \pm 7 & \pm 67 & \pm 0.003 & \pm 2 \\
\hline II & 34.5 & 1.967 & 16 & 532 & 0.061 & 32 \\
\hline$(n=13)$ & \pm 0.3 & \pm 103 & \pm 5 & \pm 30 & \pm 0.007 & \pm 4 \\
\hline III & $4(0.0$ & 3.286 & 25 & 340 & 0.081 & 28 \\
\hline$(n=10)$ & \pm 0.2 & \pm 86 & \pm 5 & \pm 24 & \pm 0.004 & \pm 2 \\
\hline
\end{tabular}

${ }^{1}$ Functional residual capacity.

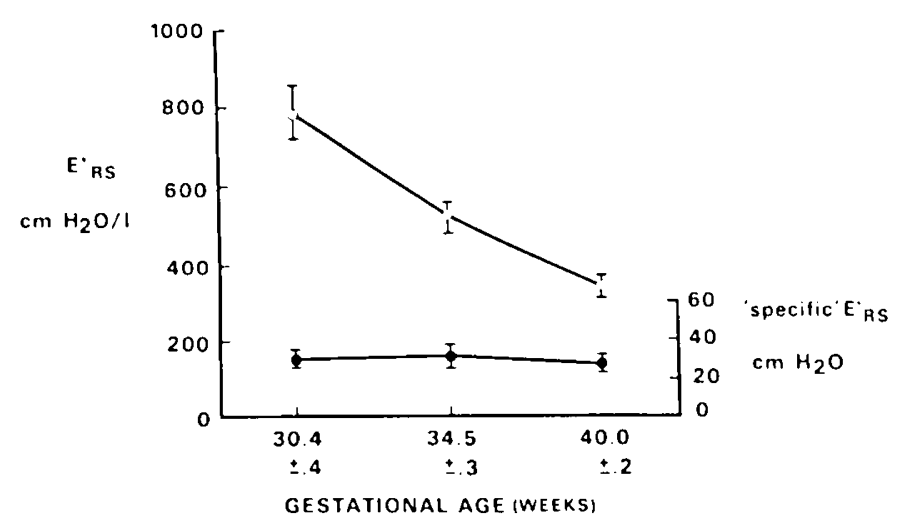

Fig. 3. The effective clastance of the respiratory system ( $1:^{\prime}$ ks. decreases significantly with increasing gestational age whereas "specific" E' 
gests that the changes with age are lung volume dependent, which possibly alters the properties of the respiratory muscles. Whether neural recruitment of intercostal muscles is important to explain the increased $E^{\prime}{ }_{k s}$ in preterm infants remains unknown. Neural recruitment seems important in animals and is probably vagally mediated $(4,6)$.

The $\mathrm{E}^{\prime}{ }_{\mathrm{r}}$ has been used as an index of ventilatory stability (4$6)$. Increased $E^{\prime}{ }_{n s}$, reflecting high impedance of the respiratory system, would increase the stability of the tidal volume when the system is presented with external elastic loads (4-6). Exactly what benefit the preterm infant might derive from this increased $E^{\prime}{ }_{k s}$ is questionable. Loads imposed during feeding, by change in position, or by partial nasal obstruction may be "physiologically adapted" to body size and may not require more of a compensatory mechanism in preterm than in term infants. Preterm infants do have a higher pulmonary impedance than term infants, probably because of their morphologically immature lungs, with increased interstitial/air space ratio (12). This high pulmonary impedance coupled with an unusually compliant chest wall may represent an unstable compromise as compared to the term infant, with a low pulmonary impedance and a stiffer chest wall. At least, if regular breathing is taken as an index of good respiratory stability, preterm infants have little or no stability (11).

\section{CONCLUSION}

We suggest that the increased $E^{\prime}{ }_{\text {Rs }}$ observed in preterm infants is lung volume dependent. This may alter the intrinsic properties of the respiratory muscles, by altering the geometry of the thorax and eventually the force/length characteristics of these muscles. We further suggest that this increased $E^{\prime}{ }_{k s}$, despite being accepted traditionally as an index of increased ventilatory stability, is not of much benefit to preterm infants who have the most unstable respiration at a time when $E^{\prime}{ }_{R S}$ is maximum. Finally, if $\mathrm{E}^{\prime}{ }_{\mathrm{RS}}$ is an index of mechanical stability of the respiratory system, the inference would be that periodic breathing and apnea seen in preterm infants are independent of the mechanical properties of the respiratory system.

\section{REFERENCES AND NOTES}

1. Adler, S. M., Thach. B. T., and Frantz, I. D.: Ventilatory stability of the premature infant. Pediat. Res., 9: 393 (1975)

2. Bryan, A. C.: Personal communication.

3. Fenner, A., Schalk, U., Hoenicke, H., Wendenburg, A., and Roehling. T.: Periodic breathing in premature and neonatal babies: Incidence, breathing pattern, respiratory gas tensions, response to changes in the composition of ambient air. Pediat. Res., 7: 174 (1973).

4. Krauss, A. N., and Auld, P. A. M.: Pulmonary gas trapping in premature infants. Pediat. Res., 5: 10 (1971).

5. Lynne-Davies, P., Couture, J., Pengelly, L. D., and Milic-Emili, J.: Immediate ventilatory response to added inspiratory elastic loads in cats. J. Appl. Physiol., 30: 512 (1971).

6. Lynne-Davies, P., Couture, J., Pengelly, L. D., West, D., Bromage, P. R., and Milic-Emili, J.: Partitioning of immediate ventilatory stability to added elastic loads in cats. J. Appl. Physiol., 30: 814 (1971).

7. Mead, J.: Mechanical factors in breathing. In: J. B. L. Howell and E. J. M. Campbell: Breathlessness, p. 139 (Blackwell, Oxford, 1966).

8. Nelson, N. M., Prod'hom, L. S., Cherry, R. B., Lipsitz, P. J., and Smith, C. A.: Pulmonary function in the newborn infant. V. Trapped gas in the normal infant's lung. J. Clin. Invest., 42: 1850 (1963).

9. Olinsky, A., Bryan, M. H., and Bryan, A. C.: Response of newborn infants to added respiratory loads. J. Appl. Physiol., 37: 190 (1974).

10. Rigatto, H., and Brady, J. P.: A new nosepiece for measuring ventilation in preterm infants. J. Appl. Physiol., 32: 423 (1972).

11. Rigatto, H., and Brady, J. P.: Periodic breathing and apnea in preterm infants. I. Evidence of hypoventilation possibly due to central respiratory depression. Pediatrics, 50: 202 (1972).

12. Thurlbeck, W. M.: Postnatal growth and development of the lung. Amer. Rev. Resp. Dis., 111: 803 (1975).

13. This research was supported by Medical Research Council of Canada Grant MA-4980 and The Children's Hospital of Winnipeg Research Foundation, Inc.

14. We are grateful to Dr. V. Chernick for comments and criticisms, and to Mrs. $M$. Szajcz for typing and helping in the preparation of the manuscript .

15. Requests for reprints should be addressed to: H. Rigatto, M.D., Department of Paediatrics, Women's Centre, 700 William Ave., Winnipeg, Manitoba R3E OZ3 (Canada).

16. Received for publication May 4, 1976.

17. Accepted for publication December $1,1976$.

\title{
The Effect of Maternal Starvation on the Metabolic Response to Cold of the Newborn Rabbit
}

\author{
J. L. EDSON'11' AND D. IIULL \\ Department of Child Health, University Hospital and Medical School, Nothingham, England
}

\section{Summary}

Acute starvation of the pregnant rabbit before delivery leads to lipid mobilization, the circulating concentrations of free fatty acids (FFA) increase, and more fatty acids cross the placenta and are stored as triglyceride in fetal tissues, particularly the liver and adipose tissue. Thus the newborns from these unfed does are born with larger fat stores than normal.

In this investigation the responses of newborns of unfed and fed does were compared with respect to aspects of the metabolic responses to birth and subsequent cold exposure. It was found that at $2 \mathrm{hr}$ of age the newborns of unfed does had higher circulating concentrations of FFA and triglycerides. The glucose and glycerol concentrations were similar in the two groups, but after $2 \mathrm{hr}$ of cold exposure the newborns of fed does had much higher blood concentrations of both glucose and glycerol. In both, a large increase in FFA concentration was seen. The newborns of unfed and fed does had similar minimal metabolic rates, 